\title{
Cross-Country Spillovers in East Africa: A Global Vector Autoregressive Analysis
}

\author{
Daniel Njoora $^{1}$, Olusanya E. Olubusoye ${ }^{2}$, Patrick Weke ${ }^{3}$ \\ ${ }^{1}$ Pan African University, Institute of basic Sciences, Technology and Innovation, Department of Mathematics, Nairobi, Kenya \\ ${ }^{2}$ University of Ibadan, Department of statistics, Ibadan, Nigeria \\ ${ }^{3}$ University of Nairobi, School of Mathematics, Nairobi, Kenya \\ Email address: \\ Danielngugi15@gmail.com (D. Njoora), Nigeria.busoye2001@yahoo.com (O. E. Olubusoye), pweke@uonbi.ac.ke (P. Weke)
}

\section{To cite this article:}

Daniel Njoora, Olusanya E. Olubusoye, Patrick Weke. Cross-Country Spillovers in East Africa: A Global Vector Autoregressive Analysis. American Journal of Theoretical and Applied Statistics. Vol. 4, No. 3, 2015, pp. 125-137. doi: 10.11648/j.ajtas.20150403.18

\begin{abstract}
The recent financial crisis raises important issues about transmission of financial shocks across borders. This paper uses the global vector autoregressive model as developed in Dees, di Mauro, Pesaran and Smith (2007) to study crosscountry interlinkages among East African countries. The paper uses trade weights to capture the importance of the foreign variables. Results reveal that there is no evidence of strong international linkages across countries in East Africa. Results also reveal that the variable in which a shock is simulated is the main channel through which-in the shortrun-shocks are transmitted, while the contribution of other variables becomes more important over longer horizons.
\end{abstract}

Keywords: Global VAR, Linkages, VARY*, Spillovers, Linkages

\section{Introduction}

East African economies have undergone remarkable changes over the past ten years. Cross-border ownership of assets and investment has increased, revealing important benefits and new risks associated with integration. The financial and economic interlinkages between East African countries have increased significantly over the past years. The formation of the East Africa Community (EAC) has been one of the major drivers of closer East Africa integration. Moreover, the number of countries in the EAC has increased from 3 to 5 after Rwanda and Burundi joined the organization.

Trade between East African countries has increased rapidly: for instance, in 2010, the EAC launched its own common market for goods, labor and capital within the region with the goal of creating a common currency and eventually a full political federation. In 2013, a protocol was signed outlining the member states' plans for launching a monetary union within 10 years. Despite challenges on these establishments, this is a clear indication that trade and financial interactions have increased among these countries.

Much as trade has gained an increase, financial integration has also proceeded apace. Banks across East Africa have gained a dominant position in the banking systems in most countries. The share of foreign banks in terms of assets of local banking systems has increased rapidly over the last decade. As a result, these banks have become the main source of capital in terms of funding and foreign direct investment (FDI) for private investors in these countries.

For these countries, these closer linkages bring clear benefits but also carry risks. Trade links and financial capital inflows from more developed countries in this region like Kenya make it possible for other countries to boost their potential growth faster than they otherwise could achieve. As the countries rely on each other for capital and trade, economic slowdowns and financial market turmoil in any of these countries spill over across other countries. For instance, when Kenya experienced the post-election violence in 20072008 , this triggered a sudden stop of trade flows in the region, which contributed to a deep crisis in addition to the global financial crisis.

In this paper, we attempt to explore the cross-country linkages between East Africa countries using the GVAR framework. The main motivation of the paper is that our study has a very major difference in country coverage and the key variables studied compared to similar regional studies. As explained later in the paper, a key step of GVAR analysis is to construct, for domestic variables of each country in the system corresponding foreign variables, usually a weighted average of corresponding variables of its partners. For 
example, if the variable of interest is inflation rates, then its corresponding foreign variable (foreign inflation) is constructed as a weighted average of the inflation of its partners. The weighting scheme usually reflects the strength of economic ties of a particular country with its foreign partners.

In existing literatures, the selection of weights often varies. In this work we follow the literature of Pesaran et al. (2004), DdPS (2007), Feldkircher and Korhonen (2012) whereby we use weights based on trade flows. Other works use geographical distance based weights, Vansteenkiste (2007) whereas Galesi and Sgherri (2009) adopt weights based on bank lending data across countries.

In the paper, we focus on co-movements between our variables of interest. The objective is to show how simulated shocks are propagated across the countries. The variables in our model are inflation rates, interest rates and exchange rates. We follow the bulk of existing literature in including oil prices as a global variable. The country sample includes all countries across East Africa, that is, Kenya, Uganda, Tanzania, Rwanda and Burundi. The model has yielded interesting results in that there is no evidence of strong international linkages across countries in East Africa. Results also reveal that the variable in which a shock is simulated is the main channel through which-in the shortrun-shocks are transmitted, while the contribution of other variables becomes more important over longer horizons.

The rest of the paper is structured as follows: section 2 describes the analytical basis of the global VAR framework and the data used in the analysis. Section 3 presents estimation results. Section four analyses country-specific global shocks by using GIRFs and GFEVD from the GVAR model. Conclusion is included in section 5 .

\section{The GVAR Model (2000-2013)}

\subsection{Structure of the Model}

In order to capture the importance of cross-country spillovers among countries, we build a GVAR model, following Pesaran, Schuermann and Weiner (2004) and DdPS (2007). The GVAR model is a cross-country framework which allows the investigation of interdependencies among countries. It is generally composed of several country economies modeled by corresponding vector autoregressive (VAR) models. Each country model is linked with others by including foreign-specific variables. In this way, each country is potentially affected by developments in other countries, thus the need to use a global macroeconometric modeling approach in the analysis of regional propagation of shocks.

In our paper, foreign-specific variables are constructed using trade weights, hence indicating the importance of each country's trade partner. By using trade weights, we follow the works of Pesaran et al. (2004) and DdPS (2007) who employ trade weights based on cross-country trade flows. We deviate from the fact that in the original GVAR modeling technique, financial weights are used to capture the foreign variables.
Other literature employ financial weights, for instance Galesi and Sgherri (2009), Vansteenkiste (2007) uses weights based on geographical distances among regions whereas Hiebert and Vansteenkiste (2007) adopt weights based on sectoral input-output tables across industries.

Our GVAR model covers 5 countries in East Africa. Since all countries are modeled individually, the GVAR model is composed by 5 VARY*, that is, VAR models augmented by weakly exogeneousI (1) foreign variables. Countries included in the analysis are Kenya, Uganda, Tanzania, Rwanda and Burundi. In each country VARY* model, country specific variables are related to deterministic variables-such as time trend-and a set of country-specific foreign variables, calculated as weighted variables of the corresponding country-specific variables for the remaining countries.

Each country will be modeled as a VARY* model as shown below

$$
\begin{aligned}
& y_{i t}= a_{i 0}+a_{i 1} t+\phi_{i 1} y_{i, t-1}+\cdots+\phi_{i p} y_{i, t-p}+\Lambda_{i 0} y^{*}{ }_{i t}+ \\
& \Lambda_{i 1} y^{*}{ }_{i, t-1}+\cdots+\Lambda_{i q} y^{*}{ }_{i, t-q}+u_{i t}
\end{aligned}
$$

Where

$$
\begin{gathered}
t=1, \ldots, T \\
i=1, \ldots, N, t=1, \ldots, T
\end{gathered}
$$

$y_{i t}$ is a $k_{i} \times 1$ vector of country specific domestic variables $y^{*}{ }_{i t}$ is the $k^{*}{ }_{i} \times 1$ vector of foreign variables specific to country $i$

$\phi_{i p}$ is a $k_{i} \times k_{i}$ matrix of coefficients associated to lagged domestic variables

$\Lambda_{i 0}$ is a $k_{i} \times k^{*}{ }_{i}$ matrices of coefficients related to contemporaneous foreign variables

$\Lambda_{i j}$ is a $k_{i} \times k^{*}{ }_{i}$ matrices of coefficients related to the lagged foreign variables $(j=1, \ldots, q)$

$a_{i 0}$ is a $k_{i} \times 1$ vector of fixed intercepts

$a_{i 1}$ is a $k_{i} \times 1$ vector of coefficients of the deterministic time trend

$u_{i t}$ is a $k_{i} \times 1$ vector of country specific shocks assumed to be serially uncorrelated with a zero mean and a non-singular covariance matrix. Specifically $u_{i t} \sim i i d\left(0, \sum_{u}\right)$.

Moreover, a cross-country correlation among the idiosyncratic shocks is allowed. In particular it is assumed that

$$
E\left(u_{i t}, u^{\prime}{ }_{i t}\right)=\left\{\begin{array}{c}
\sum_{i j} \text { for } t=t^{\prime} \\
0 \text { for } t \neq t
\end{array}\right.
$$

Therefore, by construction, the GVAR model allows for interactions among the different economies through two channels: (a) the contemporaneous interrelation of domestic variables, $y_{i t}$, with foreign-specific variables, $y_{i t}^{*}$, and with their lagged values; (b) the contemporaneous dependence of shocks in country $i$ on the shocks in country $j$, as described by the cross-country covariances, $\sum_{i j}$, where $\sum_{i j}=$ $\operatorname{cov}\left(u_{i t}, u_{j t}\right)=E\left(u_{i t}, u^{\prime}{ }_{j t}\right)$, for $i \neq j$.

The domestic variables included in the country-specific models are the following: inflation rates, interest rates and exchange rates. Oil prices enter the model as a global 
variable.

The foreign variables are specific to each country and represent the influence of trade partners for a given country. These are calculated as weighted averages of the corresponding variables for that country. Specifically the set of foreign-specific variables for country $i, y^{*}$, is given by:

$$
y^{*}=\sum_{j=1}^{N} w_{i j} x_{j t}
$$

Where

$w_{i i}=0, \forall i=1, \ldots, N$ and $\sum_{j=1}^{N} w_{i j}, \forall i, j=1, \ldots, N$.

The weights, $w_{i j}$ for $j=1, \ldots, N$, capture the importance of country $j$ for country $i$. They are based on cross-country trade flows.

The domestic variables and foreign variables are grouped as

$$
Z_{i t}=\left(y_{i t}, y^{*}{ }_{i t}\right)
$$

Each country model in (1) is then written as

$$
A_{i 0} Z_{i t}=a_{i 0}+a_{i 1} t+A_{i 1} Z_{i, t-1}+\cdots+A_{i 1} Z_{i, t-p}+u_{i t}
$$

where it is assumed that $p=q$ for ease of computation

In equation (3)

$$
\begin{gathered}
A_{i 0}=\left(I_{k i},-\Lambda_{i 0}\right) \\
A_{i 1}=\left(\phi_{i 1}, \Lambda_{i 1}\right) \\
\vdots \\
A_{i p}=\left(\phi_{i p}, \Lambda_{i p}\right)
\end{gathered}
$$

And the $A_{i p}$ coefficient matrices are all of size $k_{i} \times\left(k_{i}+\right.$ $k^{*}{ }_{i}$ ). Equation (3) can be treated like a VAR (p) model by multiplying throughout by $A_{i 0}{ }^{-1}$.

To examine the endogeneity of the foreign variable $y_{i t}^{*}$, we need to solve the entire (global) model. Stacking over the countries model can be written as

$$
\begin{gathered}
y_{t}=a_{0}+a_{1} t+\Phi_{1} y_{t-1}+\cdots+\Phi_{p} y_{t-p}+\Lambda_{0} w y_{t}+ \\
\Lambda_{1} w y_{t-1}+\cdots+\Lambda_{p} w y_{t-p}+u_{t}
\end{gathered}
$$

Where

$$
\begin{gathered}
y_{t}, a_{0}, a_{1}, y_{t-1} \ldots y_{t-p} \text { are } N k \times 1, \\
\Phi_{1} \ldots \Phi_{p} \text { and } \Lambda_{0}, \Lambda_{1}, \ldots, \Lambda_{p} \text { are } N k \times N k
\end{gathered}
$$

The solution of the stacked model is obtained as

$$
\begin{array}{r}
y_{t}=\left(I_{k N}-\Lambda_{0} w\right)^{-1}\left(a_{0}+a_{1} t+\Phi_{1} y_{t-1}+\cdots+\Phi_{p} y_{t-p}+\right. \\
\left.\Lambda_{1} w y_{t-1}+\cdots+\Lambda_{p} w y_{t-p}+u_{t}\right)
\end{array}
$$

Provided the innovations $u_{t}$ are independent in the time dimension, the endogeneity of the regressors $w y_{t}$ follows from

$$
E\left(w y_{t} u_{t}\right)=w\left(I_{k N}-\Lambda_{0} w\right)^{-1} E\left(u_{t} u_{t}^{\prime}\right)
$$

Pesaran et al. (2002) assume that the weight matrices $w_{i j}$ are diagonal with $w_{i j}=\operatorname{diag}\left(w_{i j}^{1}, \ldots, w_{i j}^{k}\right)$ and that $\sum_{j=0}^{N}\left(w_{i j}^{m}\right)^{2} \rightarrow 0$, as $N \rightarrow \infty$, for all $i$ and $m$

However, this implies that asymptotically the foreign variables have no explanatory power in the model. Asymptotic properties of such model should not be used as small sample guidance for our estimators if we actually expect some degree of cross sectional dependence in our model.

The assumption $\sum_{j=0}^{N}\left|w_{i j}^{m}\right| \leq c<\infty$, for all $i$ and $m$, where the constant $c$ does not depend on the sample size N. This is clearly a weaker assumption but it turns out to be powerful enough to allow us derive asymptotic properties of our model.

We can also build a simple version of our GVAR model from each country models represented by equation (1) as follows.

We collect all the domestic variables of all the countries to create the global vector

$$
y_{t}=\left(\begin{array}{c}
y_{1 t} \\
y_{2 t} \\
\vdots \\
y_{N t}
\end{array}\right)
$$

Which is a $k \times 1$ vector containing all endogeneous variables, where $k=\sum_{i=1}^{N} k_{i}$. Following the step that gives rise to equation (1) and the one above, we obtain the identity

$$
Z_{i t}=w_{i} y_{t}
$$

For $i=1, \ldots, N$, where $w_{i}$ is a country-specific link matrix of dimensions $\left(k_{i}+k_{i}^{*}\right) \times k$ constructed on the basis of trade weights. This identity allows writing each country model in terms of the global vector in (8). By substituting (9) in (1), we obtain

$$
A_{i} w_{i} y_{i t}=a_{i 0}+a_{i 1} t+B_{i 1} w_{i} y_{i, t-1}+\cdots+B_{i p} w_{i} y_{i, t-p}
$$

The individual country models are then stacked, yielding the model for all the variables in the global model $y_{t}$ to obtain

$$
G y_{t}=a_{0}+a_{1} t+\sum_{j=1}^{p} H_{j} y_{t-j}+u_{t}
$$

Where

$$
G=\left(\begin{array}{c}
A_{1,0} w_{1} \\
\vdots \\
A_{N, 0} w_{N}
\end{array}\right)
$$

$$
H_{j}=\left(\begin{array}{c}
A_{1, j} w_{1} \\
\vdots \\
A_{N, j} w_{N}
\end{array}\right), a_{0}=\left(\begin{array}{c}
a_{1,0} \\
\vdots \\
a_{N, 0}
\end{array}\right), a_{1}=\left(\begin{array}{c}
a_{1,1} \\
\vdots \\
a_{N, 1}
\end{array}\right), u_{t}=\left(\begin{array}{c}
u_{1, t} \\
\vdots \\
a_{N, t}
\end{array}\right)
$$

Pre-multiplying equation (11) by $G^{-1}$ yields an autoregressive representation of the GVAR (p) model shown below

$$
y_{t}=b_{0}+b_{1} t+\sum_{j=1}^{p} F_{j} y_{t-j}+\varepsilon_{t}
$$

Where 


$$
F_{j}=G^{-1} H_{j}, b_{0}=G^{-1} a_{0}, b_{1}=G^{-1} a_{1} \text { and } \varepsilon_{t}=G^{-1} u_{t}
$$

Equation (12) can be treated like any other VAR equation of order $\mathrm{p}$.

\subsection{Properties of the Data Series}

Our data set includes 5 countries from East Africa. The sample period spans, on a quarterly basis, from 2000Q1 to 2013Q3. For each country we consider the following variables: inflation rates, exchange rates and interest rates obtained from the national authorities of the respective countries.

The country-specific foreign variables are constructed using trade weights. In particular, the trade of country $i$ with country $j$ is considered to be the total exports and imports from the period 2004-2011.

We investigate the order of integration of each variable under study by means of formal unit root tests. We discuss the ADF unit root t-statistics as well as those based on weighted symmetric estimation of ADF type regressions introduced by Park and Fuller (1995). The latter tests denoted by Ws, exploit the time reversibility of stationary autoregressive processes in order to increase their power performance. Leybourne, Kim and Newbold (2005) and Pantula, Gonzalez, Farias and Fuller (1995) provide evidence of superior performance of the weighted symmetric test statistic compared to the standard ADF test or the GLS-ADF test proposed by Elliot et al. (1996). The lag length employed in the ADF and Ws unit root tests has been selected by the Akaike Information Criterion (AIC). Results of the ADF and WS statistics are provided for the level, first differences and second differences of all the country specific domestic and foreign variables as well as global variables. When testing the levels, two types of regressions have been computed: one including both an intercept and a trend, and another including an intercept only. When testing first and second differences, only the intercept is included. Asymptotic 5\% critical values for both statistics have been employed. The results are reported in tables 2, 3 and 4 . The $95 \%$ critical values are indicated in the third column for regressions with and with no trend. The unit root hypothesis at the 5\% level of significance is not rejected for all domestic, foreign and the global variables.

Table 1. Weight Matrix based on fixed weights.

\begin{tabular}{llllll}
\hline country & rwanda & kenya & uganda & tanzania & burundi \\
\hline rwanda & 0 & 0.0983761 & 0.1196532 & 0.0532244 & 0.1072535 \\
kenya & 0.442186 & 0 & 0.7372607 & 0.7488049 & 0.2510997 \\
uganda & 0.3773395 & 0.517266 & 0 & 0.150186 & 0.4867709 \\
tanzania & 0.1112848 & 0.3483198 & 0.099574 & 0 & 0.1548759 \\
burundi & 0.0691896 & 0.036038 & 0.0435121 & 0.0477847 & 0 \\
\hline
\end{tabular}

Table 2. Unit root test results for domestic variables at the 5\% significance level.

\begin{tabular}{|c|c|c|c|c|c|c|c|}
\hline Domestic Variables & Statistic & Critical Value & rwanda & kenya & uganda & tanzania & burundi \\
\hline inf (with trend) & $\mathrm{ADF}$ & -3.45 & -5.4171 & -4.1712 & -3.9697 & -6.3820 & -4.8858 \\
\hline inf (with trend) & WS & -3.24 & -5.7648 & -4.4711 & -5.0028 & -6.6417 & -5.1293 \\
\hline inf (no trend) & $\mathrm{ADF}$ & -2.89 & -5.4186 & -4.2241 & -3.5906 & -6.3971 & -4.9299 \\
\hline $\inf$ (no trend) & WS & -2.55 & -5.7941 & -4.5176 & -4.5980 & -6.6598 & -5.1691 \\
\hline Dinf & $\mathrm{ADF}$ & -2.89 & -5.8135 & -6.7319 & -6.8172 & -6.7142 & -8.5082 \\
\hline Dinf & WS & -2.55 & -6.1495 & -7.0027 & -3.4995 & -7.0892 & -8.7924 \\
\hline DDinf & $\mathrm{ADF}$ & -2.89 & -6.2798 & -6.2581 & -4.0608 & -8.0522 & -6.6873 \\
\hline DDinf & WS & -2.55 & -6.6166 & -6.6947 & -4.3282 & -8.3351 & -7.1333 \\
\hline exc (with trend) & $\mathrm{ADF}$ & -3.45 & -3.6331 & -6.0477 & -5.1100 & -5.9118 & -4.4346 \\
\hline exc (with trend) & WS & -3.24 & -2.3780 & -6.1804 & -4.7805 & -6.0616 & -4.4125 \\
\hline exc (no trend) & $\mathrm{ADF}$ & -2.89 & -4.1532 & -6.0651 & -5.0802 & -5.8028 & -4.4635 \\
\hline exc (no trend) & WS & -2.55 & -2.1383 & -6.2273 & -4.8339 & -6.0020 & -4.2994 \\
\hline Dexc & $\mathrm{ADF}$ & -2.89 & -5.6601 & -6.9817 & -7.3188 & -5.5866 & -6.6787 \\
\hline Dexc & WS & -2.55 & -5.5670 & -7.3460 & -7.6653 & -5.4044 & -5.7036 \\
\hline DDexc & $\mathrm{ADF}$ & -2.89 & -7.1903 & -7.2466 & -7.5913 & -7.2045 & -8.0991 \\
\hline DDexc & WS & -2.55 & -7.2784 & -7.7113 & -7.9295 & -7.5641 & -8.8900 \\
\hline int (with trend) & $\mathrm{ADF}$ & -3.45 & -6.7020 & -4.5298 & -5.0533 & -5.7577 & -5.7907 \\
\hline int (with trend) & WS & -3.24 & -6.3029 & -4.5884 & -4.9363 & -5.4614 & -5.9809 \\
\hline int (no trend) & $\mathrm{ADF}$ & -2.89 & -6.4890 & -4.4180 & -4.8196 & -5.1851 & -5.8335 \\
\hline int (no trend) & WS & -2.55 & -6.5372 & -4.2741 & -4.9275 & -5.1624 & -5.9970 \\
\hline Dint & $\mathrm{ADF}$ & -2.89 & -9.7974 & -7.4423 & -6.0772 & -6.5831 & -7.5631 \\
\hline Dint & WS & -2.55 & -6.4099 & -7.5136 & -5.8732 & -6.4763 & -8.0331 \\
\hline DDint & $\mathrm{ADF}$ & -2.89 & -10.363 & -5.9243 & -7.0431 & -9.9380 & -10.8254 \\
\hline DDint & WS & -2.55 & -7.7119 & -6.0285 & -6.9330 & -9.8297 & -11.3713 \\
\hline
\end{tabular}


Table 3. Unit Root Tests for the Foreign Variables at the 5\% Significance Level.

\begin{tabular}{|c|c|c|c|c|c|c|c|}
\hline Foreign variable & Statistic & Critical value & rwanda & kenya & uganda & tanzania & burundi \\
\hline infs (trend) & $\mathrm{ADF}$ & -3.45 & -3.9697 & -3.9697 & -3.7402 & -3.9697 & -3.9697 \\
\hline infs (trend) & WS & -3.24 & -5.0028 & -5.0028 & -3.9677 & -5.0028 & -5.0028 \\
\hline infs (no trend) & $\mathrm{ADF}$ & -2.89 & -3.5906 & -3.5906 & -3.7612 & -3.5906 & -3.5906 \\
\hline infs (no trend) & WS & -2.55 & -4.5980 & -4.5980 & -3.9956 & -4.5980 & -4.5980 \\
\hline Dinfs & $\mathrm{ADF}$ & -2.89 & -6.8172 & -6.8172 & -6.7574 & -6.8172 & -6.8172 \\
\hline Dinfs & WS & -2.55 & -3.4995 & -3.4995 & -7.0235 & -3.4995 & -3.4995 \\
\hline DDinf & $\mathrm{ADF}$ & -2.89 & -4.0608 & -4.0608 & -6.2533 & -4.0608 & -4.0608 \\
\hline DDinf & WS & -2.55 & -4.3282 & -4.3282 & -6.9302 & -4.3282 & -4.3282 \\
\hline excs (trend) & $\mathrm{ADF}$ & -3.45 & -5.2984 & -4.4104 & -5.7549 & -5.8798 & -5.0718 \\
\hline excs (trend) & WS & -3.24 & -5.3574 & -4.5269 & -5.8358 & -5.9334 & -5.1650 \\
\hline excs (no trend) & $\mathrm{ADF}$ & -2.89 & -5.3364 & -4.4483 & -5.8081 & -5.9114 & -5.1213 \\
\hline excs (no trend) & WS & -2.55 & -5.4098 & -4.5199 & -5.8917 & -5.9900 & -5.2099 \\
\hline Dexcs & $\mathrm{ADF}$ & -2.89 & -7.4421 & -6.2559 & -6.7551 & -7.3853 & -6.9980 \\
\hline Dexcs & WS & -2.55 & -7.8599 & -6.6718 & -7.1413 & -7.7658 & -7.4242 \\
\hline DDexc & $\mathrm{ADF}$ & -2.89 & -7.4314 & -6.7954 & -7.0989 & -7.3335 & -7.1169 \\
\hline DDexc & WS & -2.55 & -7.8816 & -7.0697 & -7.5909 & -7.8271 & -7.5565 \\
\hline ints (trend) & $\mathrm{ADF}$ & -3.45 & -3.4725 & -5.11 & -4.3480 & -4.0247 & -3.5720 \\
\hline ints (trend) & WS & -3.24 & -3.6872 & -4.6388 & -4.5056 & -4.1784 & -3.7095 \\
\hline ints (no trend) & $\mathrm{ADF}$ & -2.89 & -3.2560 & -4.8700 & -4.1904 & -3.9158 & -3.2296 \\
\hline ints (no trend) & WS & -2.55 & -3.4911 & -4.6134 & -4.1787 & -3.9041 & -3.4706 \\
\hline Dints & $\mathrm{ADF}$ & -2.89 & -6.7967 & -5.8527 & -7.8125 & -7.0893 & -6.9757 \\
\hline Dints & WS & -2.55 & -6.9505 & -5.2322 & -7.9063 & -7.1888 & -7.1028 \\
\hline DDint & $\mathrm{ADF}$ & -2.89 & -8.6701 & -7.4101 & -7.9962 & -6.5924 & -6.7629 \\
\hline DDint & WS & -2.55 & -8.6134 & -6.5496 & -8.3707 & -7.0019 & -6.8185 \\
\hline
\end{tabular}

Table 4. unit root test for the global variable at the 5\% significance level.

\begin{tabular}{llll}
\hline Global Variables & Test & Critical Value & Statistic \\
\hline poil (with trend) & ADF & -3.45 & -5.2370335 \\
poil (with trend) & WS & -3.24 & -5.4398825 \\
poil (no trend) & ADF & -2.89 & -5.0521658 \\
poil (no trend) & WS & -2.55 & -5.2925515 \\
Dpoil & ADF & -2.89 & -6.8166702 \\
Dpoil & WS & -2.55 & -7.1716318 \\
DDpoil & ADF & -2.89 & -6.4942482 \\
Dpoil & WS & -2.55 & -6.9426192 \\
\hline
\end{tabular}

\section{Estimation}

\subsection{Conditions for the GVAR Estimation}

Given the considerable dimension of the GVAR model with respect to a traditional VAR model, it is not possible to estimate the global model using the traditional procedure. This is because it would involve the estimation of a number of parameters greater than the number of available observations. This shortcoming is solved by having an estimation procedure based on a country-by-country estimation, rather than a full system estimation, given the weak exogeneity of the foreign-specific variables. The weights used for the construction of the foreign variables are computed rather than estimated. In doing so, the estimation procedure reduces considerably the number of unrestricted parameters to be estimated.

Pesaran et al. (2004) in Galesi and Sgheri (2009) indicate three further requirements as sufficient conditions for the validity of the GVAR methodology:
1. The global model must be dynamically stable. Specifically the Eigen values of the F matrix in (12) must be either on or inside the unit circle.

2. The weights must be relatively small, such that $\sum_{j=1}^{N} w_{i j}^{2} \rightarrow 0$ as $N \rightarrow \infty$, for $i=1,2, \ldots, N$.

3 . The cross-dependence of the idiosyncratic shocks must be sufficiently small, so that $\frac{\sum_{j=1}^{N} \sigma_{i j, l s}}{N} \rightarrow 0$, as $N \rightarrow \infty$, for all $i, l, s$. Where $\sigma_{i j, l s}=\operatorname{cov}\left(u_{i l t}, u_{j s t}\right)$ is the covariance of the variable $l$ in country $i$ with the variable $s$ in country $j$.

All the three requirements are met in our GVAR model. First the model is dynamically stable: the moduli of the Eigen values of the $F$ matrix in 13 are all on or within the unit circle. Specifically, 3 Eigen values lie on the unit circle as reported while the rest lie inside the unit circle as reported in table 12.

Majority of the weights are 'granular' for each country, that is, they are not too close to one. The largest weights are observed for Kenya towards Uganda and Tanzania with 0.7372607 and 0.74880049 respectively.

Lastly, the idiosyncratic shocks are weakly correlated. Among the variables in levels, exchange rates appears to be the most correlated, with a maximum of 0.275157 for Uganda and a minimum of 0.092029 for Burundi. Moreover, with respect to variables in differences, we observe a fall in the degree of correlation. The VECMY residuals are obtained from the estimation of each VECMY* model, containing both the domestic and foreign variables. The VECMY residuals are generally weakly correlated and in some cases negatively weakly correlated for all the variables under study. This is a clear indication that the inclusion of the foreign 
variables in the country model estimation cleans the common factor among the variables, thereby yielding weakly correlated residuals. In this way, this condition allows us to simulate shocks which are mainly country-specific.

\subsection{Estimation of the Country-Specific Models}

Given that the variables under study have a unit root, we individually estimate each country-VARY* model in its vector error correcting form, Johansen (1992). The rank of the cointegrating space for each country is computed using
Johansen's trace and maximal eigen value statistics as set out in Pesaran, Shin and Smith (2000) for models with weakly exogeneous I(1) regressors. The final selection of the rank orders is determined by the trace statistic, which in small samples is known to have better power properties than the maximal Eigen value statistic. The results are reported in tables 5-8. In cases where cointegration is found, each country-VARY* model is estimated under its vector errorcorrecting (VECMY*) form.

Table 5. Detailed Cointegration Results for the Maximum Eigenvalue Statistic at the 5\% Significance Level.

\begin{tabular}{llllll}
\hline Country & Rwanda & Kenya & Uganda & Tanzania & Burundi \\
\hline Number of endogeneous variables & 3 & 4 & 3 & 3 & 3 \\
Number of foreign variables & 4 & 3 & 4 & 4 & 4 \\
$r=0$ & 72.2582 & 69.5551 & 55.0400 & 51.3710 & 59.8783 \\
$r=1$ & 59.7675 & 47.1868 & 34.5418 & 32.7366 & 21.1041 \\
$r=2$ & 27.9424 & 22.0356 & 14.3360 & 19.4847 & 16.1002 \\
$r=3$ & & 20.2550 & & & \\
\hline
\end{tabular}

Table 6. Detailed Cointegration Results for the Trace Statistic at the 5\% Significance Level.

\begin{tabular}{llllll}
\hline Country & rwanda & kenya & uganda & tanzania & burundi \\
\hline Number of endogenous variables & 3 & 4 & 3 & 3 & 3 \\
Number of foreign (star) variables & 4 & 3 & 4 & 4 & 4 \\
$r=0$ & 159.9681 & 159.0324 & 103.9178 & 103.5922617 & 97.08264 \\
$r=1$ & 87.70989 & 89.47732 & 48.87775 & 52.22128167 & 37.20437 \\
$r=2$ & 27.94238 & 42.29056 & 14.33595 & 19.48465381 & 16.10018 \\
$r=3$ & & 20.25498 & & & \\
\hline
\end{tabular}

Table 7. Critical Values for Trace Statistic at the 5\% Significance Level (MacKinnon, Haug, Michelis, 1999).

\begin{tabular}{llllll}
\hline Country & rwanda & kenya & uganda & tanzania & burundi \\
\hline Number of endogenous variables & 3 & 4 & 3 & 3 & 3 \\
Number of foreign (star) variables & 4 & 3 & 4 & 7 & 4 \\
$r=0$ & 71.56 & 91.81 & 71.56 & 71.56 & 71.56 \\
$r=1$ & 45.9 & 64.54 & 45.9 & 45.9 & 45.9 \\
$r=2$ & 23.63 & 41.03 & 23.63 & 23.63 & 23.63 \\
$r=3$ & & 20.98 & & & \\
\hline
\end{tabular}

Table 8. Cointegrating relationships for the individual VARY models.

\begin{tabular}{ll}
\hline country & number of cointegrating relations \\
\hline rwanda & 3 \\
kenya & 3 \\
uganda & 2 \\
tanzania & 2 \\
burundi & 1 \\
\hline
\end{tabular}

\subsection{Weak Exogeneity Tests}

The main assumption underlying the estimation of the individual country VARY* models is the weak exogeneity of the foreign variables. This assumption is compatible with a certain degree of weak dependence across $u_{i t}$ as discussed in Pesaran, Schuermann and Weiner (2004). A formal test of this assumption for the country specific foreign variables and the observed global variables is carried out as described in Johansen (1992) and Harbo, Johansen, Nielsen and Rahbek (1998). Testing for weak exogeneity involves the marginal model of the foreign variables.
The weak exogeneity test in this work contains the $\mathrm{F}$ statistics for testing the weak exogeneity of the foreign variables. The test statistics have been generated with the critical values at 5\% level of significance and the given degrees of freedom as shown in table 9 . The weak exogeneity assumption is not rejected for most of the foreign variables, despite some exceptions. In particular, the assumption is rejected at the $5 \%$ significance level for Kenyan inflation. Therefore, given that only 1 out of 19 foreign variables fail to satisfy the weak exogeneity assumption, we consider these outcomes as acceptable, thereby justifying the estimation procedure of each country model in the GVAR. 
Table 9. Test for weak exogeneity at 5\% significance level.

\begin{tabular}{lllllll}
\hline Country & F test & Fcrit_0.05 & infs & excs & ints & poil \\
\hline Rwanda & $\mathrm{F}(3,6)$ & 4.7571 & & & & \\
Kenya & $\mathrm{F}(3,18)$ & 3.1599 & 5.9758 & 4.5338 & 0.6712 & \\
Uganda & $\mathrm{F}(2,7)$ & 4.7374 & & & & \\
Tanzania & $\mathrm{F}(2,33)$ & 3.2849 & 0.1098 & 0.7379 & 1.2047 & 0.7937 \\
Burundi & $\mathrm{F}(1,20)$ & 4.3512 & 0.2617 & 3.2293 & 4.7369 & 0.1106 \\
\hline
\end{tabular}

\subsection{Impact Elasticities}

The contemporaneous effects of foreign variables on their domestic counterparts are provided together with t-ratios computed based on standard, as well as White and NeweyWest adjusted variance matrices. These contemporaneous effects are given by the estimated coefficients on the contemporaneous foreign variables and can be interpreted as impact elasticities between domestic and foreign variables. They are particularly informative as regards the international linkages between the domestic and foreign variables. High elasticities between domestic and foreign variables imply strong co-movements between the two. In addition to these coefficient estimates, standard errors and t-values are also calculated. White's heteroskedasticity robust and NeweyWest heteroskedasticity and autocorrelation consistent standard errors as well as the corresponding t-values are also computed. The results are listed in table 10 . The results in the table above indicate that, the impact elasticities of all the variables are statistically significant for all the countries. All the values are positive but lower than one. For a given country, impact elasticities lower than one indicate that the domestic variables do not overreact to a variation in the foreign variable of its trade partners, while an impact elasticity greater than one indicate that the domestic variables overreacts to a variation in the foreign variables of the corresponding trade partners. Moreover, these findings give us already some insights with respect to the dynamics of the GIRFs: there is no evidence of strong international linkages across countries.

Table 10. Contemporaneous effects of foreign variables on their domestic counterparts.

\begin{tabular}{|c|c|c|c|c|}
\hline & & inf & exc & int \\
\hline RWANDA & Coefficient & $4.351 \times 10^{-9}$ & 0.003841 & -0.0939 \\
\hline RWANDA & Standard error & $2.943 \times 10^{-9}$ & 0.032030 & 0.1419 \\
\hline RWANDA & t-Ratio & 1.4786474 & 0.119930 & -0.6618 \\
\hline RWANDA & White's Adjusted SE & $8.013 \times 10^{-10}$ & 0.029187 & 0.1516 \\
\hline RWANDA & t-Ratio & 5.4303699 & 0.131615 & -0.6194 \\
\hline RWANDA & Newey-West's Adjusted SE & $7.73 \times 10^{-10}$ & 0.026376 & 0.1467 \\
\hline RWANDA & t-Ratio & 5.6264517 & 0.145642 & -0.6403 \\
\hline KENYA & Coefficient & $6.76 \times 10^{-10}$ & 0.8312 & -0.5008 \\
\hline KENYA & Standard error & $8.95 \times 10^{-10}$ & 0.1945 & 0.2975 \\
\hline KENYA & t-Ratio & 0.755774 & 4.2737 & -1.6835 \\
\hline KENYA & White's Adjusted SE & $5.44 \times 10^{-10}$ & 0.2737 & 0.2851 \\
\hline KENYA & t-Ratio & 1.2439378 & 3.0365 & -1.7566 \\
\hline KENYA & Newey-West's Adjusted SE & $4.67 \times 10^{-10}$ & 0.2995 & 0.2848 \\
\hline KENYA & t-Ratio & 1.4472997 & 2.7755 & -1.7582 \\
\hline UGANDA & Coefficient & 22100185 & 0.9492 & -0.0659 \\
\hline UGANDA & Standard error & 44139876 & 0.1379 & 0.1725 \\
\hline UGANDA & t-Ratio & 0.5006853 & 6.8822 & -0.3821 \\
\hline UGANDA & White's Adjusted SE & 27955489 & 0.1438 & 0.1406 \\
\hline UGANDA & t-Ratio & 0.7905491 & 6.5998 & -0.4689 \\
\hline UGANDA & Newey-West's Adjusted SE & 29982063 & 0.1279 & 0.1373 \\
\hline UGANDA & t-Ratio & 0.7371136 & 7.4219 & -0.4803 \\
\hline TANZANIA & Coefficient & $1.197 \times 10^{-8}$ & 0.0552 & 0.0996 \\
\hline TANZANIA & Standard error & $1.156 \times 10^{-8}$ & 0.0843 & 0.1318 \\
\hline TANZANIA & t-Ratio & 1.0353234 & 0.6544 & 0.7558 \\
\hline TANZANIA & White's Adjusted SE & $8.435 \times 10^{-9}$ & 0.0632 & 0.1128 \\
\hline TANZANIA & t-Ratio & 1.4186784 & 0.8723 & 0.8828 \\
\hline TANZANIA & Newey-West's Adjusted SE & $8.455 \times 10^{-9}$ & 0.0499 & 0.0849 \\
\hline TANZANIA & t-Ratio & 1.4153838 & 1.1054 & 1.1733 \\
\hline BURUNDI & Coefficient & $3.069 \times 10^{-9}$ & 0.0716 & 0.2428 \\
\hline BURUNDI & Standard error & $3.869 \times 10^{-9}$ & 0.0901 & 0.2808 \\
\hline BURUNDI & t-Ratio & 0.7933594 & 0.7942 & 0.8646 \\
\hline BURUNDI & White's Adjusted SE & $7.026 \times 10^{-10}$ & 0.0726 & 0.2691 \\
\hline BURUNDI & t-Ratio & 4.3679583 & 0.9858 & 0.9023 \\
\hline BURUNDI & Newey-West's Adjusted SE & $7.23 \times 10^{-10}$ & 0.0533 & 0.2652 \\
\hline BURUNDI & t-Ratio & 4.2428634 & 1.3419 & 0.9156 \\
\hline
\end{tabular}




\section{Dynamic Analysis}

Impulse responses refer to the time profile of the effects of variable specific shocks or identified shocks (such as monetary policy or technology shocks, identified using a suitable economic theory) on the future states of a dynamical system and thus, on all the variables in the model. In this work different types of shocks are simulated. For instance, we simulate a negative global shock to a domestic variable, a shock to a global variable and a shock to domestic variables.

\subsection{Generalized Impulse Response Functions}

The impulse responses of shocks to specific variables considered for the GVAR model are the Generalized Impulse Response ResponseFuctions (GIRFS), introduced in Koop et al. (1996) and adapted to VAR models in Pesaran and Shin (1998).

This relatively new approach differs in a number of ways from traditional Orthogonalized Impulse Responses (OIRs) in Sims (1980). First, it does not orthogonalize the residuals of the system, as it takes into account the historical correlations among the variables, summarized by the estimated variance-covariance matrix. For this reason, it does not require any a priori economic-based restrictions and its outcome is invariant to the ordering of the variables in the model. Second, since the shocks are not identified, the GIRFs cannot provide information about the causal relationships among the variables. This shortcoming limits the potential; applications of the GIRFs, especially for purposes of policy simulation. Nonetheless, GIRFs have a comparative advantage with respect to the traditional OIRs in the context of multicountry frameworks such as the GVAR model, Galesi and Sgherri (2009). Infact, they can provide interesting insights on how shocks internationally propagate, by unveiling potential linkages among different national economies. In addition, it is actually a difficult task to employ traditional OIRs in a GVAR, since there is no reasonable way to order the countries in the model.

In our application, we analyze the dynamic properties of our GVAR model by simulating either a positive or a negative standard error shock to each country's variable. The scope of this simulation is to determine the degree of intercountry financial spillovers: in other words, we seek to analyze how each country responds to a specific shock.

For instance, the GIRFs associated to one standard error negative shock to Kenyan inflation on its partners' inflation are plotted in figure 2 below. For each region, the charts show the dynamic response of each variable over a time horizon of 10 years which has been used as our forecast horizon.

The graphs in figure 1 indicate that Uganda and Tanzania have a significant response to a one standard error (s.e.) negative shock to Kenyan inflation as compared to Rwanda and Burundi. Rwanda and Burundi are only responding in the shortrun.
The graphs in figure 2, show the responses associated with exchange rates to one s.e shock to Kenyan inflation.The graphs indicate that there are strong fluctuations in GIRFs for Kenya, Uganda, Tanzania and Burundi in the shortrun but the trend stabilizes after 3 years. In the case of Rwanda, there are strong fluctuations for the first 3 years and a monotonic decrease in exchange rates' GIRFs in the longrun.

The graphs in figure 3 indicate that there are strong fluctuations in interest rates for the first three years but the trend stabilizes in the longrun. Moreover, there is a notable response that is observed for Kenya. The associated GIRFs monotonically decrease over the first year i.e. first four quarters but the trend thereafter is similar to the other countries.

Another form of shock simulated is a global shock to inflation. The results are represented in the graphs in figures 4, 5, 6 and 7 for the stated variables. The GIRFs for Kenyan inflation decreases for two years then stabilizes, while that of the other countries in the study keeps fluctuating for 2 years and then stabilizes. For the case of exchange rates, there is a striking fluctuation in the GIRFs for all countries as shown in the graphs above. A similar trend is observed for the response in interest rates as shown in figure 6. Other types of shocks simulated show similar trends to the ones discussed above, that is, sharp fluctuations in the shortrun-mostly 2 to 4 years and then stabilization in the longrun.

\subsection{Generalized Forecast Error Variance Decompositions}

Traditionally the forecast error variance decomposition of a VAR model is performed on a set of orthogonalised shocks, whereby the contribution of the $j^{\text {th }}$ orthogonalised innovation to the mean square error of the n-step ahead forecast of the model is calculated. In the case of the GVAR, the shocks across countries, that is $u_{i t}$ and $u_{s t}$ for $i \neq s$, are not orthogonal. In fact, there is evidence that on average, the shocks across countries are positively correlated, Smith and Galesi (2011). The standard application of the orthogonalised FEVD to the GVAR model is therefore not valid.

Results of the GFEVDs are reported in table 13.Following a shock to the Kenyan exchange rates, we observe that among the Kenyan variables, exchange rates explain most of the forecast error variance in the short run. However, the relative contribution of exchange rates decreases over time, while the opposite is for the other Kenyan and non-Kenyan variables. Hence, we observe that if a shock is simulated, the variable which explains most of the variance of the shock in the short-term is the variable in which that shock is injected. On the contrary, in the longer term, the other domestic variables gain increasing relevance.

From a global perspective, we generally observe the same dynamic behavior just highlighted in the Kenyan case: the variable in which the shock is injected explains most of the forecast error variance for all countries over the short run; its relative importance decreases over time, while the opposite is observed for the rest of the variables. 
Table 11. Average pairwise cross-section correlations (variables and residuals).

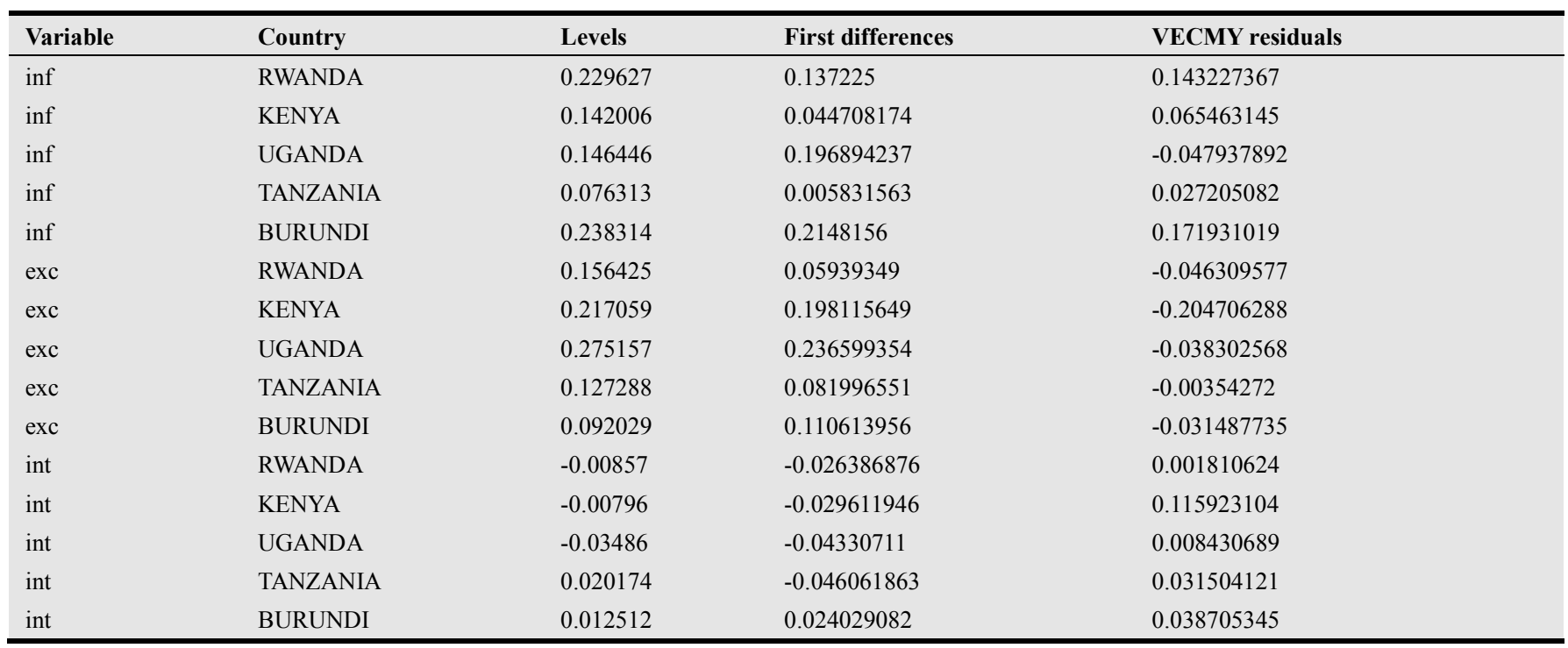

Table 12. Eigen values of the GVAR model and corresponding moduli.

\begin{tabular}{|c|c|}
\hline Eigenvalues of the GVAR Model in Descending Order & Corresponding Moduli \\
\hline $1.02981416203722+0.00000000000000 \mathrm{i}$ & 1.029814162 \\
\hline $1.00000000000000-0.00000000000001 \mathrm{i}$ & 1 \\
\hline $1.00000000000000+0.00000000000001 \mathrm{i}$ & 1 \\
\hline $0.73825198141311-0.00000000000000 \mathrm{i}$ & 0.738251981 \\
\hline $0.41446466318635-0.07890768783217 i$ & 0.652142445 \\
\hline $0.41446466318635+0.07890768783217 i$ & 0.652142445 \\
\hline $0.15171280897435+0.14459097421581 \mathrm{i}$ & 0.493157551 \\
\hline $0.15171280897435-0.14459097421581 i$ & 0.421909209 \\
\hline $0.03466968718702-0.40465695338521 i$ & 0.421909209 \\
\hline $0.03466968718702+0.40465695338521 \mathrm{i}$ & 0.406139431 \\
\hline $0.00969975457916+0.00000000000000 \mathrm{i}$ & 0.406139431 \\
\hline 0 & 0.358265217 \\
\hline 0 & 0.209578926 \\
\hline 0 & 0.209578926 \\
\hline 0 & 0.171419581 \\
\hline 0 & 0.104784157 \\
\hline 0 & 0.104784157 \\
\hline 0 & 0.020272797 \\
\hline 0 & 0.009699755 \\
\hline 0 & 0 \\
\hline 0 & 0 \\
\hline 0 & 0 \\
\hline 0 & 0 \\
\hline 0 & 0 \\
\hline$-0.02027279690868-0.00000000000000 \mathrm{i}$ & 0 \\
\hline$-0.10463456254011-0.00559714000765 \mathrm{i}$ & 0 \\
\hline$-0.10463456254011+0.00559714000765 i$ & 0 \\
\hline$-0.17141958056471+0.0000000000000 \mathrm{i}$ & 0 \\
\hline$-0.22349000598944-0.61265160196674 i$ & 0 \\
\hline$-0.22349000598944+0.61265160196674 i$ & 0 \\
\hline$-0.35826521686838+0.0000000000000 \mathrm{i}$ & 0 \\
\hline$-0.49315755115142+0.00000000000000 \mathrm{i}$ & 0 \\
\hline
\end{tabular}


Table 13. GFEVD; proportion of $N$-step ahead forecast Error variance of Kenyan exchange rates.

\begin{tabular}{|c|c|c|c|c|c|c|c|c|c|c|}
\hline Quarter & & $\mathbf{0}$ & 5 & 10 & 15 & 20 & 25 & 30 & 35 & 40 \\
\hline Kenya & Inf & 0.017 & 0.108 & 0.128 & 0.141 & 0.160 & 0.177 & 0.0194 & 0.209 & 0.223 \\
\hline Kenya & Exc & 0.577 & 0.304 & 0.254 & 0.238 & 0.228 & 0.219 & 0.210 & 0.203 & 0.196 \\
\hline Kenya & Int & 0.001 & 0.126 & 0.108 & 0.101 & 0.097 & 0.093 & 0.090 & 0.087 & 0.084 \\
\hline Rwanda & Inf & 0.010 & 0.013 & 0.013 & 0.013 & 0.014 & 0.014 & 0.015 & 0.015 & 0.016 \\
\hline Rwanda & Exc & 0.012 & 0.010 & 0.009 & 0.009 & 0.009 & 0.009 & 0.008 & 0.008 & 0.008 \\
\hline Rwanda & Int & 0.002 & 0.017 & 0.019 & 0.018 & 0.018 & 0.018 & 0.018 & 0.018 & 0.018 \\
\hline Uganda & Inf & 0.001 & 0.004 & 0.028 & 0.029 & 0.029 & 0.029 & 0.029 & 0.030 & 0.030 \\
\hline Uganda & Int & 0.011 & 0.029 & 0.030 & 0.048 & 0.049 & 0.056 & 0.059 & 0.063 & 0.067 \\
\hline Tanzania & Inf & 0.009 & 0.031 & 0.031 & 0.029 & 0.029 & 0.028 & 0.027 & 0.027 & 0.026 \\
\hline Tanzania & Exc & 0.020 & 0.080 & 0.065 & 0.062 & 0.062 & 0.062 & 0.061 & 0.060 & 0.060 \\
\hline Tanzania & Int & 0.005 & 0.011 & 0.012 & 0.014 & 0.013 & 0.014 & 0.014 & 0.014 & 0.014 \\
\hline Burundi & Inf & 0.005 & 0.005 & 0.006 & 0.006 & 0.006 & 0.006 & 0.006 & 0.005 & 0.005 \\
\hline Burundi & Exc & 0.007 & 0.014 & 0.014 & 0.014 & 0.015 & 0.015 & 0.016 & 0.016 & 0.016 \\
\hline Burundi & int & 0.001 & 0.010 & 0.010 & 0.011 & 0.013 & 0.014 & 0.015 & 0.016 & 0.017 \\
\hline
\end{tabular}

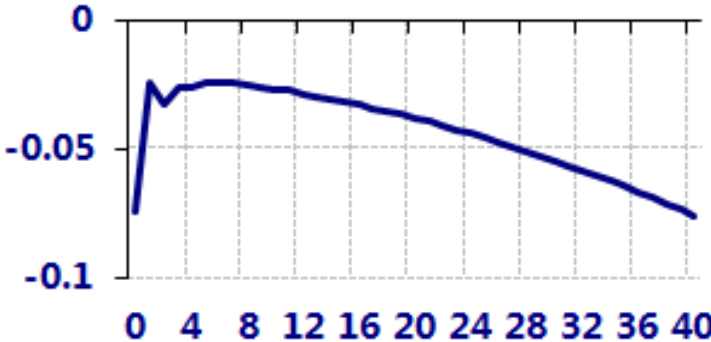

a) Kenya inflation

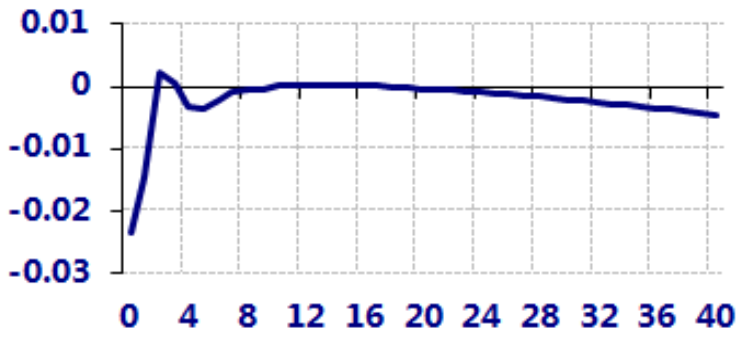

b) Rwanda inflation

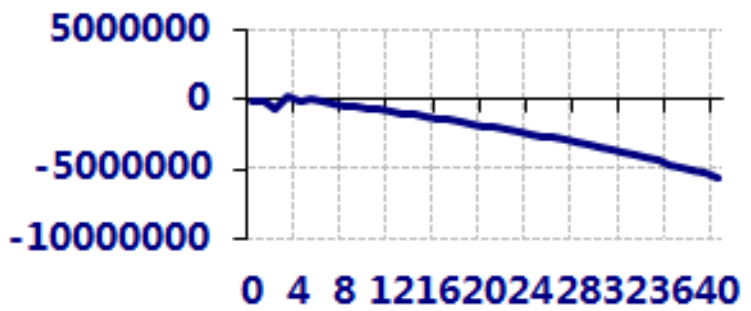

c) Uganda inflation

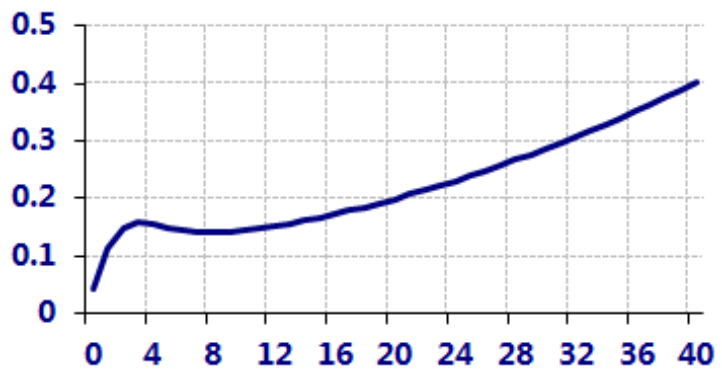

d) Tanzania inflation

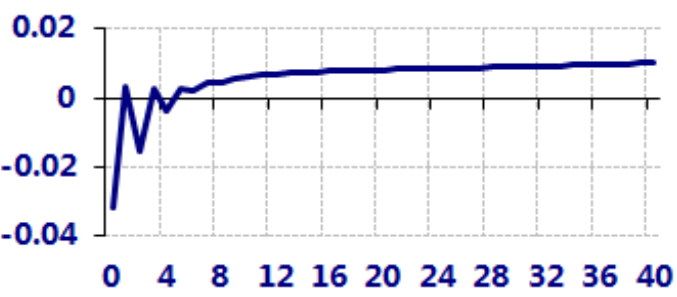

e) Burundi inflation

Figure 1. GIRFs; Response to one s.e. negative shock to Kenyan inflation

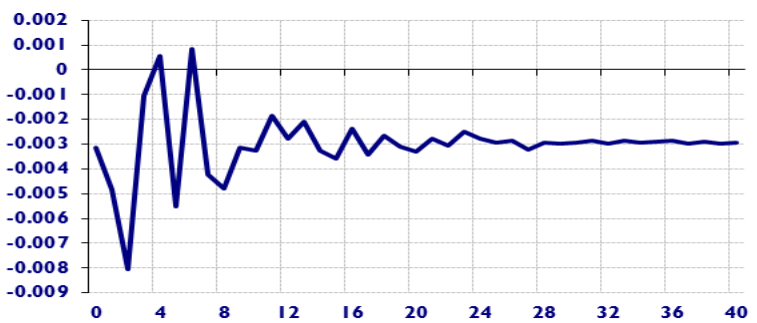

a) Kenya exchange rates

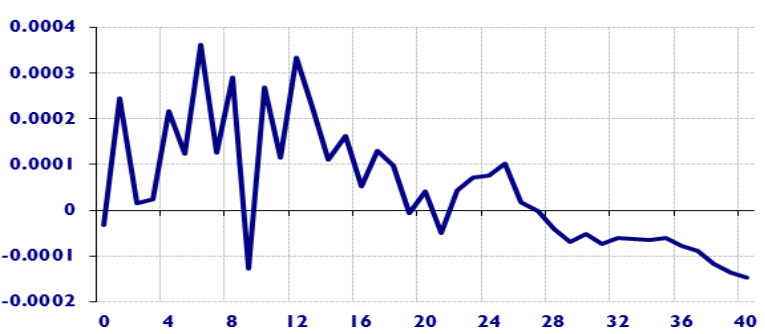

b) Rwanda exchange rates

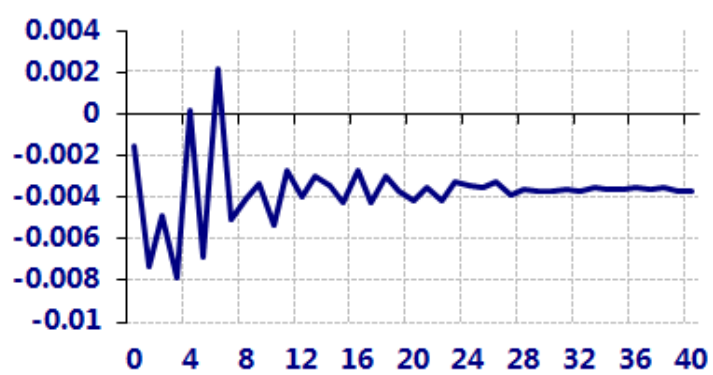

c) Uganda exchange rates 

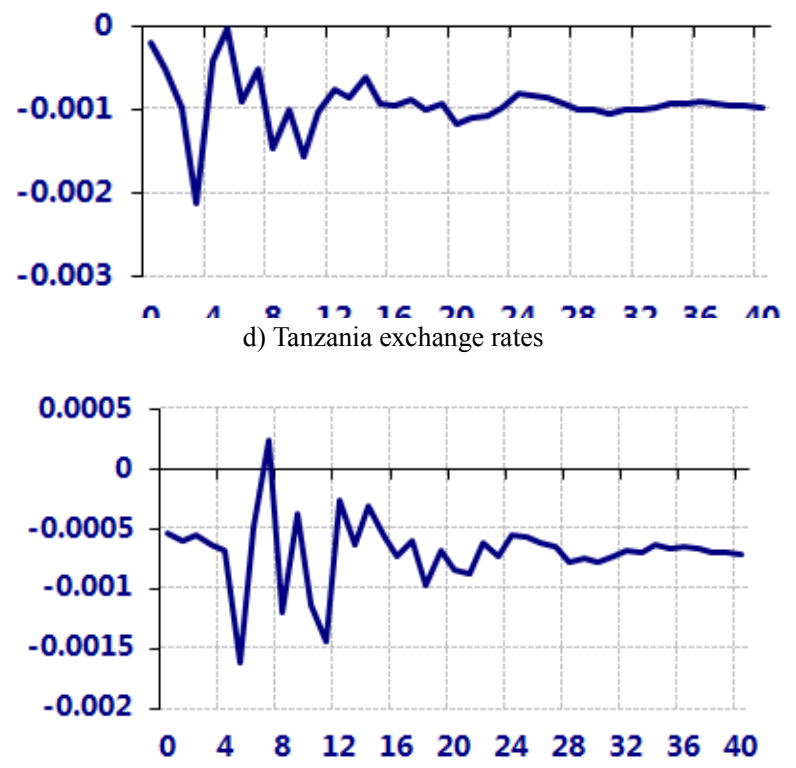

e) Burundi exchange rate

Figure 2. GIRFs; Response to one s.e shock to Kenyan inflation for exchange rates.

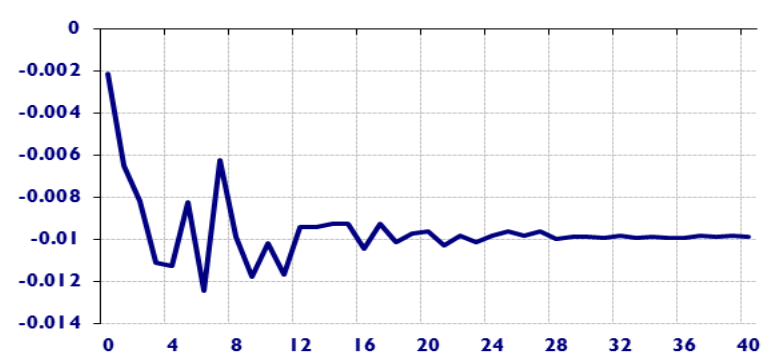

a) Kenya interest rates

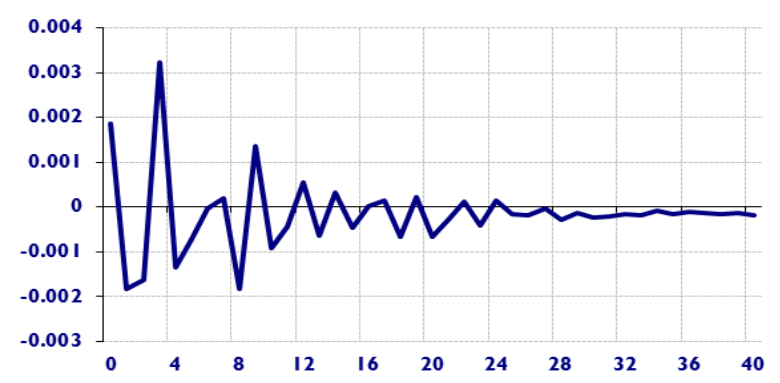

b) Rwanda interest rates

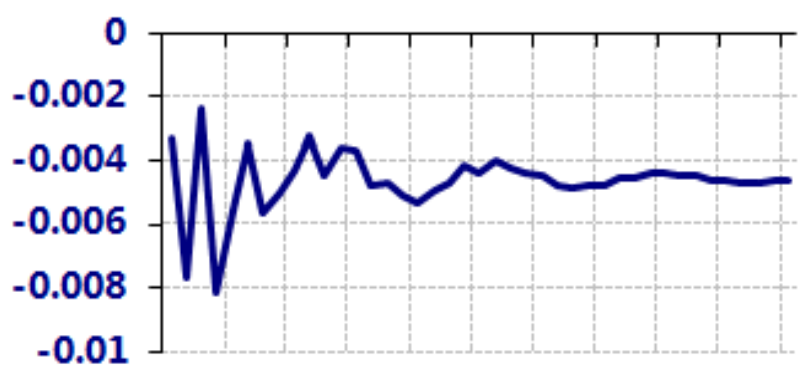

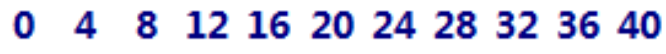

c) Uganda interest rates
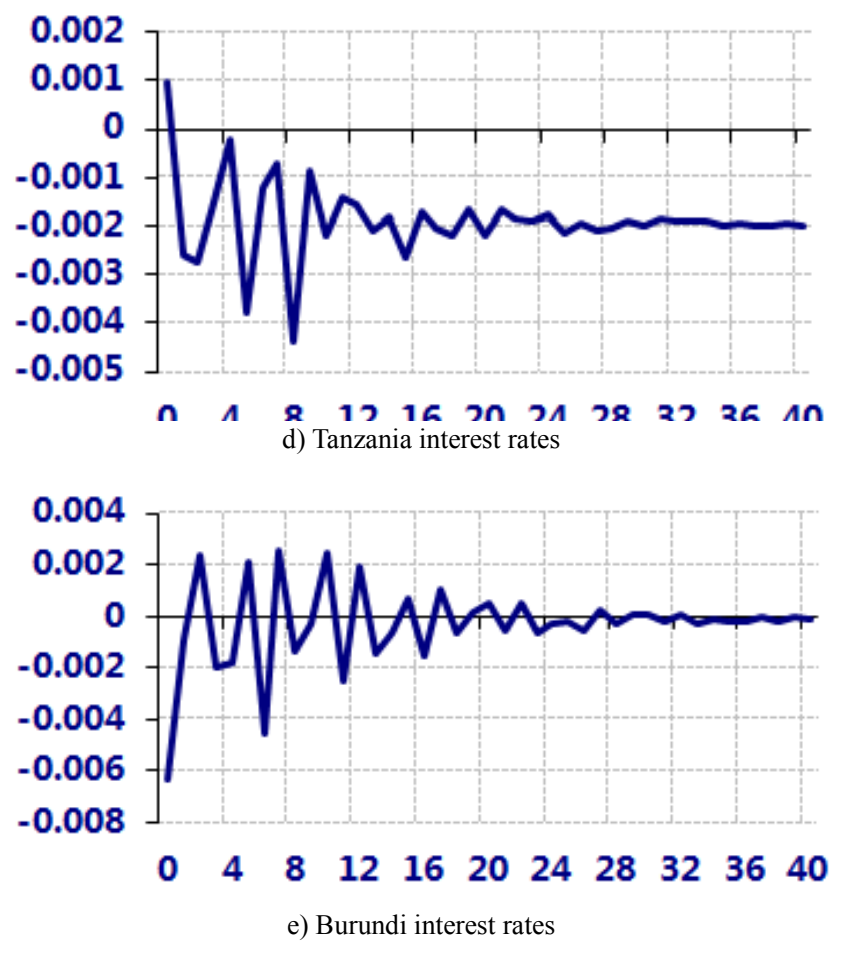

Figure 3. GIRFs; Response to one s.e shock to inflation for interest rates.
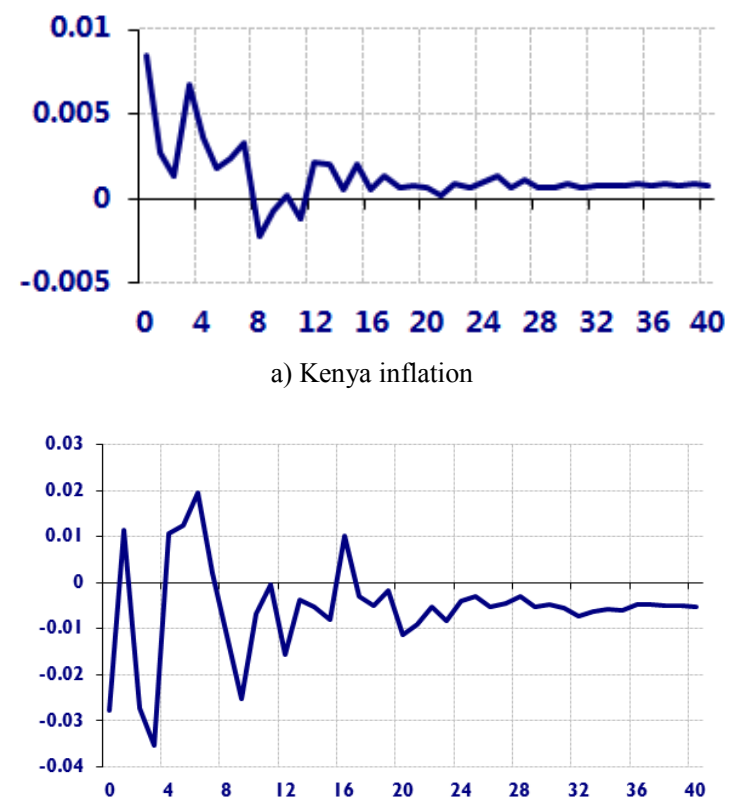

b) Rwanda inflation

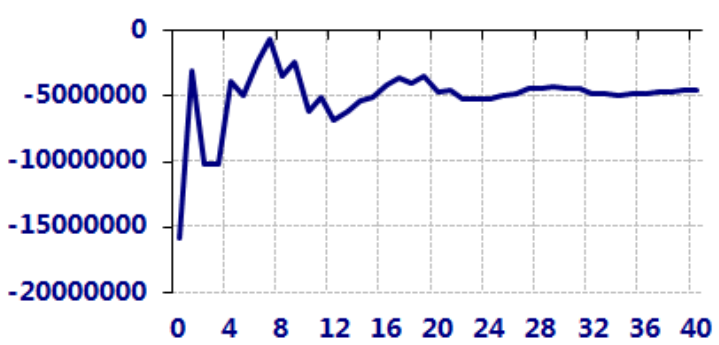

c) Uganda inflation 

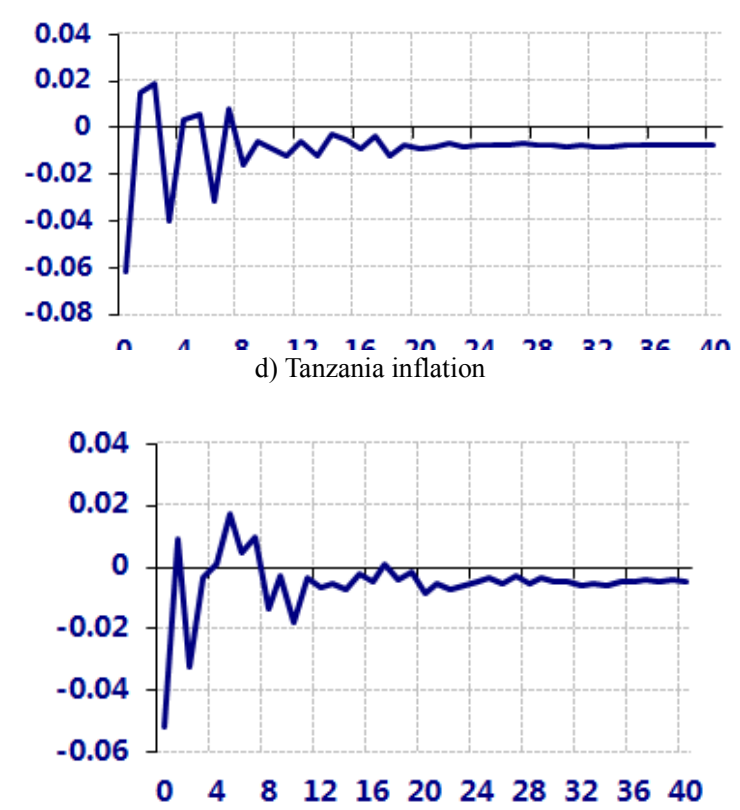

e) Burundi inflation

Figure 4. GIRFs; Response to one global s.e shock to inflation for inflation.

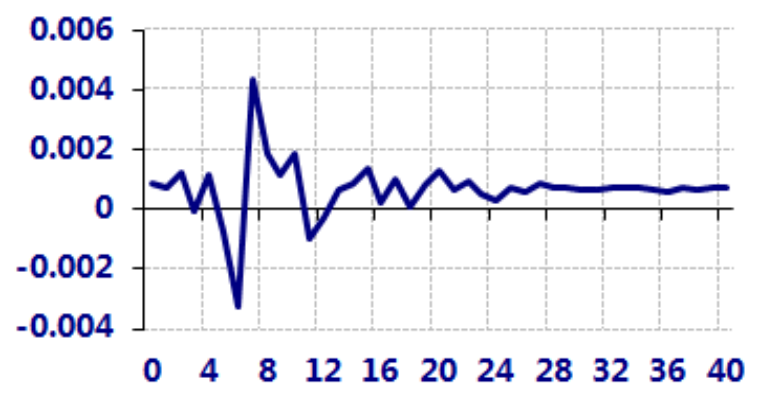

a) Kenya exchange rates

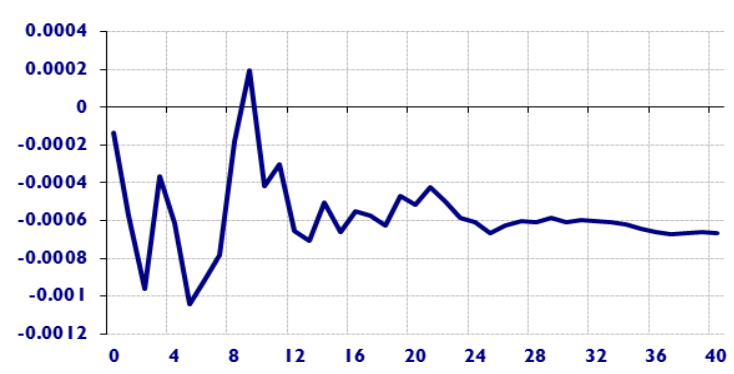

b) Rwanda exchange rates

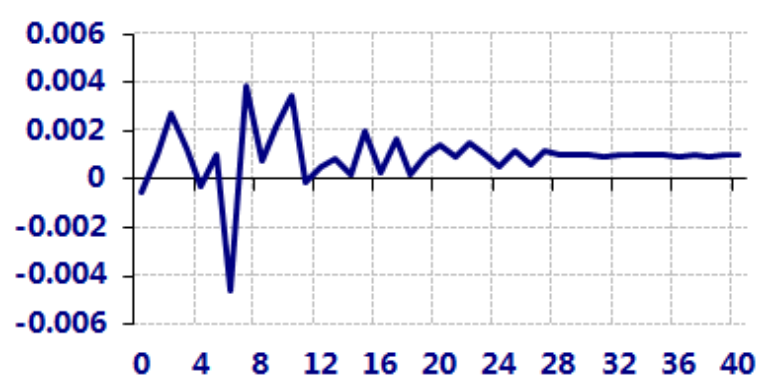

c) Uganda exchange rates
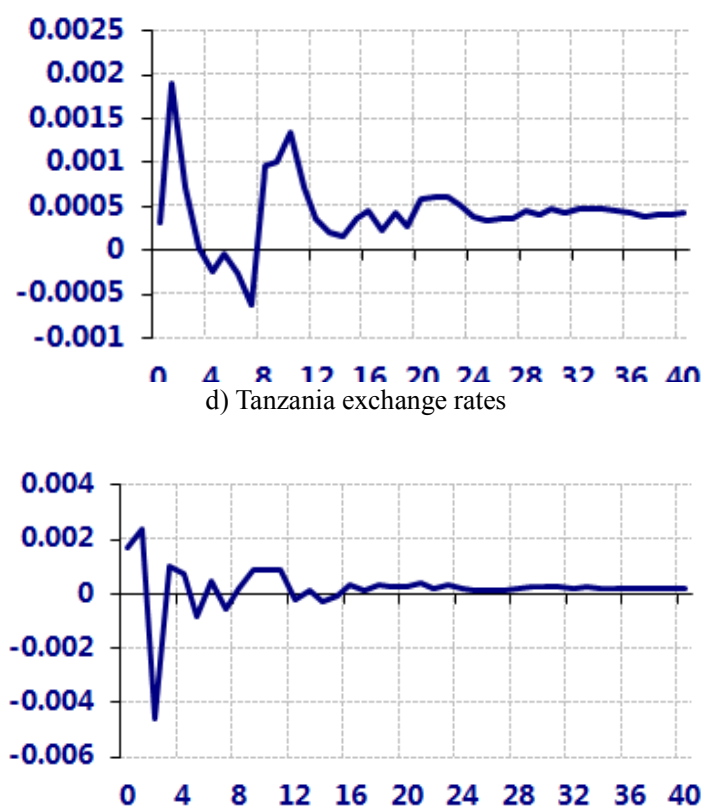

e) Burundi exchange rates

Figure 5. GIRFs; to one global s.e shock to inflation for exchange rates.

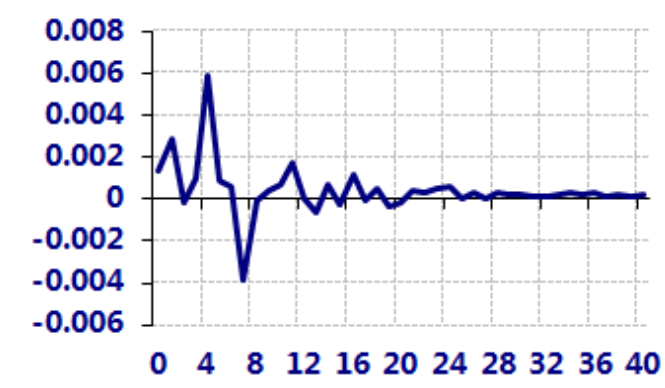

a) Kenya interest rates

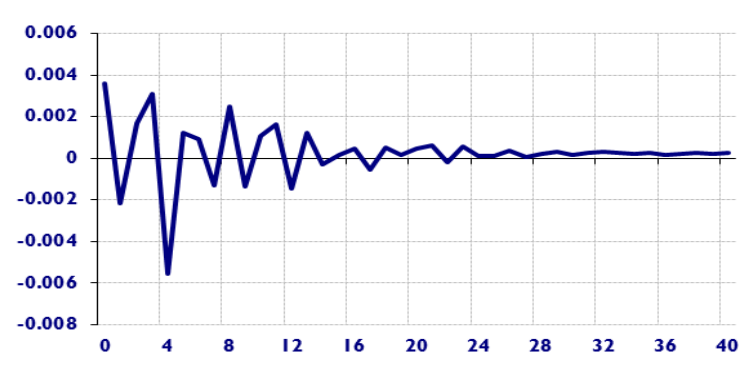

b) Rwanda interest rates

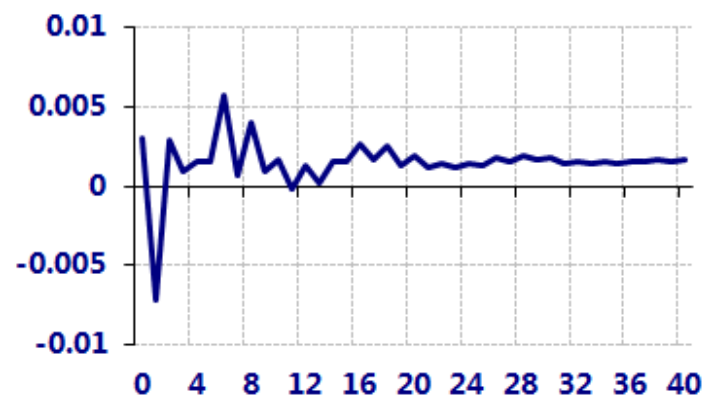

c) Uganda interest rates 

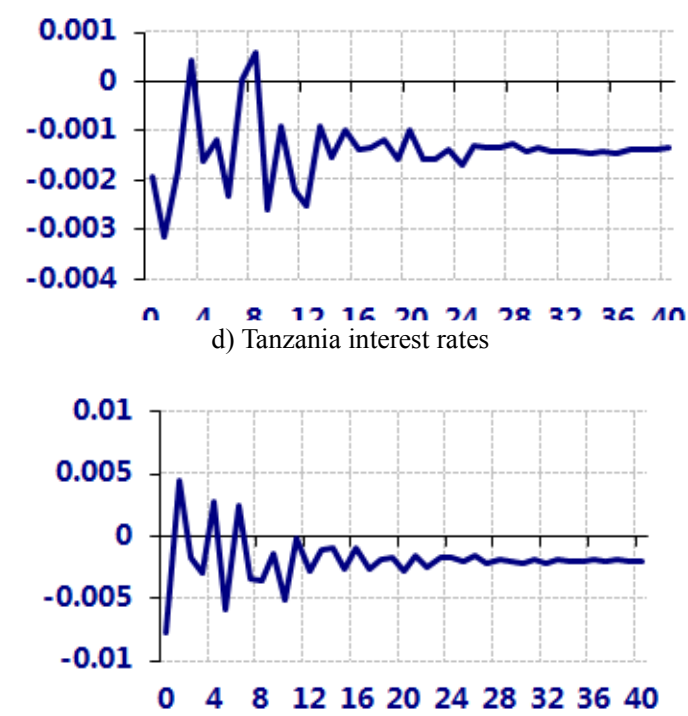

e) Burundi interest rates

Figure 6. GIRFs; to one global s.e shock to inflation for interest rates.

\section{References}

[1] Dees S., di Mauro F., Pesaran M. H. and Smith L. V. (2007). 'Exploring the international linkages of the euro area: a global VAR analysis', Journal of Applied Econometrics 22 (1), 1-38.

[2] Elliott G., Rothenberg T. and Stock J. (1996). 'Efficient tests for an autoregressive unit-root, Econometrica, 64, 813-836.

[3] Galesi A. and Sgherri S. (2009). 'regional financial spillovers across Europe: a global VAR analysis, IMF working paper series, WP/09/23.

[4] Harbor I., Johansen S., Nielsen B and Rahbek A. (1998). 'Asymptotic inference on cointegrating rank in partial systems', Journal of Business and Economic statistics 16(4), 388-399.
[5] Hiebert P. and Vansteenkiste I. (2007). 'International trade, technological shocks and spillovers in the labor market; a GVAR analysis of the US manufacturing sector, working paper series 731, European Central Bank.

[6] Johansen S. (1992). 'Cointegration in partial systems and the efficiency of the single-equation analysis', Journal of Econometrics 52 (3), 389-402.

[7] Leybourne S., Kim T. and Newbold P. (2005). 'Examination of some more powerful modifications of the Dickey-Fuller Test, Journal of time Series Analysis, Wiley Blackwell, 26 (3), 355-369.

[8] Pantula S. G., Gonzalez-Farias G. and Fuller W. A. (1994). A comparison of unit-root test criteria, Journal of Business and Economic statistics, 12, 449-459.

[9] Park H. J. and Fuller W. A. (1995). 'Alternative estimators and unit root tests for the autoregressive process', Journal of Time series analysis 16(4), 415-429.

[10] Pesaran M. H., Schuermann T. and Weiner S. M. (2004a). 'Modelling regional interdependencies using a global errorcorrecting macro-econometric model', Journal of Business and Economic statistics 22 (2), 129-162.

[11] Pesaran M. H. and Shin Y. (1998). 'Generalized impulse response analysis in Linear multivariate models', Economics Letters 58 (1), 17-29.

[12] Pesaran M. H., Shin Y. and Smith R. J. (2000). 'Structural analysis of vector error correction models with exogeneousI(1) variables', Journal of Econometrics 97(2), 293-343.

[13] Sims C. A. (1980). 'Macroeconomics and Reality', Econometrica 48 (1), 1-48.

[14] Smith L. and Galesi A. (2011).GVAR toolbox 1.1.URL wwwcfap.jbs.cam.ac.uk/research/gvartoolbox/index.html.

[15] Vansteenkiste I. (2007). 'Regional housing market spillovers in the US-lessons fron regional divergences in a common monetary policy setting, working paper series 708, European Central Bank. 